\title{
LEI MARIA DA PENHA: UM MEIO PARA COIBIR O DISCURSO DA VIOLÊNCIA CONTRA A MULHER
}

\author{
Claudete Carvalho Canezin (PPGEL - UEL) ${ }^{1}$ \\ Edina Regina Pugas Panichi (PPGEL - UEL) ${ }^{2}$
}

\section{RESUMO}

A importância da linguagem reside no fato de que a mesma é uma relação construída pelos fatos históricos e sociais, sendo exposta no dia a dia. A linguagem, portanto, funciona como mediadora entre a pessoa e a realidade cotidiana que a cerca. Infelizmente, em muitas situações, a linguagem é utilizada de forma nociva, donde é possível vislumbrar itens lexicais e avaliativos utilizados de forma pejorativa, tal como acontece nos casos de violência contra a mulher, violência esta que não precisa ser especificamente física, mas também moral e psicológica, e, neste contexto, as palavras são armas poderosas. A fim de coibir a violência contra a mulher, foi editada a Lei $\mathrm{n}^{\mathrm{o}}$ 11.340/2006, conhecida como Lei Maria da Penha, que servirá de guia para o presente estudo. Pretende-se, pois, através da análise da semântica argumentativa, voltar olhares e trazer para a pauta do estudo a análise de itens lexicais e avaliativos comuns no discurso de mulheres e homens envolvidos nos processos que tramitam na Vara Maria da Penha, inclusive, com a transcrição de um boletim de ocorrências. .

Palavras-chave: Lei Maria da Penha; Seleção Lexical; Semântica Argumentativa.

\begin{abstract}
The importance of language lies in the fact that it is a relationship built by the historical and social facts, being exposed to everyday. Language, therefore, acts as a mediator between the person and the everyday reality that surrounds it. Unfortunately, in many situations, language is used in a harmful way, where is possible to see and evaluative lexical items used pejoratively, as happens in cases of violence against women. Violence this that need not be specifically physical, but also moral and psychological, and in this context, words are powerful weapons. In order to suppress violence against women, was enacted Law No. 11.340 / 2006, known as Maria da Penha Law, and analyzed in the present study. It is intended, therefore, by analyzing the argumentative semantics, back looks and bring to the agenda the study analysis of lexical and evaluative items common in the speech of women and men involved in the proceedings before the Penha Vara Maria, including with transcription of an occurrence report.
\end{abstract}

Keywords: Maria da Penha Law; Lexical selection; Argumentative Semantics.

\footnotetext{
${ }^{1}$ Doutoranda em Estudos da Linguagem, do Programa de Pós-Graduação Stricto Sensu da UEL. Mestre em Direito Civil pelo CESUMAR. Especialista em Direito Empresarial pela UEL. Docente do Curso de Direito na Graduação e Pós Graduação da UEL. Coordenadora do NEDDIJ e NUMAPE Projetos de Extensão da UEL. Advogada.

${ }^{2}$ Docente Sênior dos Programas de Mestrado e Doutorado em Estudos da Linguagem da UEL.
} 


\section{SEMINÁRIO DE PESQUISA EM CIÊNCIAS HUMANAS - SEPECH \\ Humanidades, Estado e desafios didático-científicos \\ Londrina, 27 a 29 de julho de 2016}

\section{INTRODUÇÃO}

Seguindo os ensinamentos de Eduardo Guimarães (2002), é possível entender a linguagem como prática significativa que funciona como mediadora entre o sujeito e a realidade social que o rodeia, caracterizando-se como uma prática simbólica que se inscreve na história por fazer parte da constituição dos sentidos e dos sujeitos. Neste viés, Guimarães (2002, p. 27), chama a atenção para o fato de que a linguagem não é transparente, sendo por isso sujeita ao equívoco. Ou seja, os sentidos das "[...] expressões linguísticas significam pela relação que estas têm com o acontecimento em que funcionam". Não se trata, portanto, de uma relação referencial, simplesmente, mas de uma abordagem transversal, em que a relação da significação tem a ver com a relação integrativa do enunciado com o texto. Logo, a linguagem é uma relação construída pelos fatos históricos e sociais, sendo exposta ao cotidiano.

Nesse sentido, pensando no contexto histórico-social da linguagem, este artigo propõe refletir sobre o uso de itens lexicais que, geralmente, são empregados em um contexto de violência doméstico-familiar contra a mulher. Para a análise de itens lexicais, será feita uma abordagem da semântica argumentativa em trechos de uma discussão de um casal, gravada e transcrita, utilizada no processo da Vara Maria da Penha cujo BO $n^{0}$ 2015/155722, concedeu a Medida Protetiva para preservar a integridade física e psíquica da mulher diante das ameaças recebidas do marido. Além das informações transcritas, houve informações coletadas por meio das redes sociais que também servirão como objeto de análise.

$\mathrm{O}$ discurso violento enviado pelo marido à esposa, em uma das mensagens pelo whatsApp, demonstra claramente falas ameaçadoras: "Você não me conhece e não sabe o que isso pode gerar, eu estrago a minha vida, mas preservo a minha honra, não vou sustentar vagabunda na minha casa que se relaciona com outro homem, adúltera". (Transcrita no $\mathrm{BO}^{3}$ ). Considerar a mulher adúltera, adjetivando-a como "vagabunda" é, de certa forma, uma justificativa para agir com violência.

$\mathrm{O}$ alto índice de conflitos domésticos já detonou o mito de "lar doce lar”. As expressões mais terríveis da violência contra mulher estão localizadas em suas próprias casas que já foram um espaço seguro, com proteção e abrigo.

Para preservar a identidade das partes envolvidas, por tratar-se de segredo de justiça, os nomes serão substituídos por $\mathrm{M}$ (a mulher/esposa) e $\mathrm{H}$ (o homem/marido).

É importante ressaltar que a violência não se refere apenas à agressão física, estende-se para um campo ainda maior, como agressão psicológica, sexual e moral. Sendo assim, a fim de buscar uma forma de minimizar a violência doméstica, o governo brasileiro, sob pressão dos organismos internacionais, elaborou a Lei $\mathrm{n}^{\mathrm{o}}$ 11.340/2006, conhecida como Lei Maria da Penha.

\section{CONTEXTUALIZANDO A LEI MARIA DA PENHA}

Sabe-se que a violência de gênero contra as mulheres não é assunto recente, é prática antiga e encontra-se historicamente ligada ao lugar social que o Estado

\footnotetext{
${ }^{3}$ Processo da Vara Maria da Penha B.O no 2015/155722, que concedeu a Medida Protetiva.
} 


\section{SEMINÁRIO DE PESQUISA EM CIÊNCIAS HUMANAS - SEPECH \\ Humanidades, Estado e desafios didático-científicos \\ Londrina, 27 a 29 de julho de 2016}

e a sociedade determinavam para elas, ou seja, eram submissas aos pais e/ou aos maridos, sempre consideradas propriedade de algum homem, não tinham capacidade civil ou qualquer poder sobre a família, nos moldes do antigo pátrio poder.

Após as grandes revoluções, as mulheres ganharam espaço no cenário social, porém continuam lutando pela conquista de seus direitos e contra uma cultura de dominação masculina. Atualmente, a despeito de poucos exemplos, elas começaram a ocupar lugar de poder na sociedade, nunca antes conquistados. Apesar das conquistas, continuam sendo vítimas de violência doméstica, de preconceitos e de muitos estereótipos. Por mais que se lute, o considerado "sexo frágil" ainda sofre o peso de um passado sexista.

A violência doméstica não é marcada apenas pela violência física, mas também pela psicológica, sexual, patrimonial, moral, dentre outras, que em nosso país atinge grande número de mulheres, as quais vivem estes tipos de agressões no âmbito familiar, ou seja, na casa, espaço da família. O que deveria ser "o porto seguro," considerado como um lugar de proteção, passa a ser um local de risco para elas.

Segundo estabelece o art. 226, $\S 8^{\circ}$ da Constituição Federal: "O Estado assegurará a assistência à família na pessoa de cada um dos que a integram, criando mecanismos para coibir a violência no âmbito de suas relações". Conforme se observa, a Carta Magna demonstra, de forma expressa, a necessidade de políticas públicas no sentido de coibir e erradicar a violência doméstica.

Assim, a abrangência da Lei 11.340/2006, se destina tão somente às mulheres em situação de violência:

Art. $1^{\circ}$ Esta Lei cria mecanismos para coibir e prevenir a violência doméstica e familiar contra a mulher, nos termos do § $8^{\circ}$ do art. 226 da Constituição Federal, da Convenção sobre a Eliminação de Todas as Formas de Violência contra a Mulher, da Convenção Interamericana para Prevenir, Punir e Erradicar a Violência contra a Mulher e de outros tratados internacionais ratificados pela República Federativa do Brasil; dispõe sobre a criação dos Juizados de Violência Doméstica e Familiar contra a Mulher; e estabelece medidas de assistência e proteção às mulheres em situação de violência doméstica e familiar.

Vale destacar que, no momento em que a lei abriga a mulher, sem distinção de sua orientação sexual, o alcance da norma também atinge as lésbicas, travestis, transexuais e transgêneros que mantêm relação íntima de afeto em ambiente familiar ou de convívio. Em todos esses relacionamentos, as situações de violência contra o gênero feminino justificam especial proteção.

Nesta seara, a Lei Maria da Penha surgiu num contexto social marcado pela persistente diferença de gênero, vindo como um meio para coibir a cultura da violência e dos preconceitos contra a mulher. Assim, a importância do presente estudo reside, também, no fato de a análise da violência de gênero expressar, de forma mais clara e contundente, a desigualdade nas relações entre homens e mulheres, em nível familiar, no que tange ao discurso. Em situações de desentendimento entre um casal, por exemplo, é perceptível a presença da violência psicológica e moral.

Nessa modalidade de violência, o marido, ou o parceiro, é o principal agressor, indicando que o espaço doméstico é o lugar favorável para o exercício de 


\section{SEMINÁRIO DE PESQUISA EM CIÊNCIAS HUMANAS - SEPECH \\ Humanidades, Estado e desafios didático-científicos \\ Londrina, 27 a 29 de julho de 2016}

muitas agressões. Assim, com a finalidade de coibir qualquer forma de violência contra a mulher, foi promulgada em 2006 a Lei Maria da Penha que ganhou este nome em homenagem à Maria da Penha Maia Fernandes, biofarmacêutica cearense que foi casada com o professor universitário Marco Antonio Herredia Viveros, que tentou assassiná-la por duas vezes.

A pessoa Maria da Penha Maia, não foi a responsável pela criação da Lei Maria da Penha e sim o ela sofreu. Ela foi vítima de violência doméstica, quando em maio de 1983, seu marido disparou um tiro em suas costas enquanto ela dormia. Maria da Penha lutou por quase 20 anos para que o seu agressor fosse punido e teve a coragem de tornar público o seu caso e denunciar o Brasil no Comitê Interamericano de Direitos Humanos da Organização dos Estados Americanos - OEA.

O Brasil foi responsabilizado por esta denúncia, em 2001, e acatou as recomendações determinadas pela OEA, dentre elas a que recomendava a mudança da legislação do país devido à negligência com que tratava os casos de violência doméstica.

Para isso, o Brasil criou a Secretaria de Políticas para as Mulheres que, juntamente com o consórcio de ONGs que trabalham a causa da Mulher (Advocacy, Agende, Themis, Cladem/Ipê, Cepia e Cfemea), com o trabalho da Relatora do Projeto de Lei, e com as diversas audiências públicas realizadas em todas as capitais do Brasil, foi criada a Lei Federal 11.340/06 - Lei Maria da Penha, aprovada por unanimidade no Congresso Federal e sancionada pelo Presidente da República em 07 de agosto de 2006.

Esta Lei baseou-se ainda nos inúmeros instrumentos internacionais ratificados pelo Brasil: Convenção sobre a Eliminação de Todas as Formas de Discriminação contra a Mulher (CEDAW), o Plano de Ação da IV Conferência Mundial sobre a Mulher (1995), Convenção Interamericana para Prevenir, Punir e Erradicar a Violência contra a Mulher (Convenção de Belém do Pará, 1994), o Protocolo Facultativo à Convenção sobre a Eliminação de Todas as Formas de Discriminação contra a Mulher, além de outros instrumentos de Direitos Humanos.

Maria da Penha Maia ficou sabendo que a Lei teria o seu nome somente no dia em que a mesma foi sancionada. Foi convidada para cerimônia pela representatividade emblemática do seu caso na questão da violência doméstica contra a mulher, pela sua persistência e luta de quase 20 anos para não deixar que seu caso fosse esquecido pela Justiça e prescrevesse e, principalmente, pela coragem que teve em se expor e denunciar o seu caso na OEA, pois se não fosse a sua denúncia, talvez esta Lei ainda não existisse.

A concretização dessa Lei significa a projeção de novas possibilidades de a mulher se defender, inclusive de ofensas proferidas pelo agressor por meio da linguagem. Além disso, certamente, essa Lei é uma "luz no final do túnel" para conscientizar a sociedade de que a mulher ocupa um papel tão importante quanto o do homem.

A sociedade precisa se reeducar, ou seja, a mulher não deve continuar a ser vista de forma pejorativa. A diminuição da figura feminina é aceita socialmente e é perfeitamente perceptível, inclusive, nas falas cotidianas. Em uma discussão entre marido e mulher, por exemplo, é comum a percepção de termos que colocam a mulher em situação inferior, sendo rebaixada a um simples objeto passível de ser descartado. Nesse contexto, a lei vem como um meio de coibir esta violência. 


\title{
XI SEMINÁRIO DE PESQUISA EM CIÊNCIAS HUMANAS - SEPECH \\ Humanidades, Estado e desafios didático-científicos \\ Londrina, 27 a 29 de julho de 2016
}

\section{DA SEMÂNTICA ARGUMENTATIVA}

Oliveira (2004) elucida que o conceito de argumentação remonta ao Século V a. C, com vários e interessantes desdobramentos. Acrescenta, ainda, que a Semântica Argumentativa foi criada na França (École des Hautes Études en Sciences de Paris), por Ducrot e Anscombre. Atualmente, Marion Carel participa da continuidade desses estudos, pesquisando o valor linguístico das palavras.

Saussure (2006) nos ensina que além do valor linguístico, as noções de língua e fala são essenciais para a formação da Semântica Argumentativa. Neste sentido, a língua é a forma de realização do pensamento daquele que fala ou escreve, ressaltando ainda mais o valor linguístico no emprego das palavras.

É possível afirmar que a Semântica Argumentativa estuda o sentido construído pelo linguístico, não na língua em si, mas no discurso, no emprego da língua, buscando o sentido construído pela relação entre palavra e contexto. Assim, o significado de uma entidade lexical é a orientação que ela dá ao discurso ou à sequência de enunciados, pois segundo Bakhtin:

\begin{abstract}
Não serão palavras o que pronunciamos ou escutamos, mas verdades ou mentiras, coisas boas ou más, importantes ou triviais, agradáveis ou desagradáveis, etc. A palavra está sempre carregada de um conteúdo ou de um sentido ideológico ou vivencial. (BAKHTIN, 1997, p.95).
\end{abstract}

Portanto, o exercício da linguagem surge da relação entre o locutor e o enunciado, sendo que a Semântica Argumentativa se apresenta como a teoria da enunciação.

É possível contrapor as visões dicotômicas mais antigas, em que a língua era compreendida como uma representação individual de pensamento (subjetivismo-idealista), ou como um sistema abstraído das práticas sociais de uso (objetivismo-abstrato). Nos dias atuais, a filologia resgatou a linguística do formalismo que a isolava do campo social e nesta seara foi possível trazer para a pauta do estudo da Lei Maria da Penha a interação entre os sujeitos, a relação entre fatos e circunstâncias, o contexto social e histórico e, principalmente, o ideológico.

Colares (2008), seguindo as lições de Bakhtin, discorre que as produções linguístico-discursivas, ainda que não o intentem de forma explícita, são determinadas por ideologias, crenças e valores que saturam o discurso de seu enunciador de subjetividade. Sendo assim, toda elaboração legislativa estará inexoravelmente embebida das mais profundas ideologias e hábitos que permeiam o seio social. No caso específico da Lei Maria da Penha, isso é possível perceber através dos valores familiares e da intenção de proteger a mulher, coibindo toda e qualquer forma de violência, física ou moral.

A linguagem direta do discurso representa, de fato, uma visão subjetiva da sociedade que, para o senso comum, se projeta como neutra e universalizante. Assim, para Bakhtin e Volochínov (1997, p.36) "[...] palavra é o modo mais puro e sensível de relação social". 


\section{SEMINÁRIO DE PESQUISA EM CIÊNCIAS HUMANAS - SEPECH \\ Humanidades, Estado e desafios didático-científicos \\ Londrina, 27 a 29 de julho de 2016}

\section{ANÁLISE DE ITENS LEXICAIS EM UMA DISCUSSÃO DOMÉSTICA}

Ao conduzirmos nosso olhar para contextos que envolvem decisões com base na Lei Maria da Penha, é possível perceber itens lexicais comuns no discurso de mulheres e homens envolvidos nos processos, sendo possível também trilhar prerrogativas, a partir desses itens, sobre como a violência permeia esse discurso, colocando a mulher num papel de inferioridade. Elas são normalmente rebaixadas como seres humanos e cidadãs, contudo não deixam de colocar a família e os filhos à frente de seus interesses.

Percebe-se que as mulheres atendidas no NUMAPE - Núcleo de estudos dos direitos e defesa da mulher violentada, (Projeto de extensão da UEL), usam habitualmente certas expressões quando estão se referindo ao que sentem ao serem agredidas pelos maridos ou companheiros, expressões como: "a violência assola a família"; "põe em risco a família"; "corrói o amor e o afeto". Denotam, assim, a fragilidade feminina ao mesmo tempo em que mostram a preocupação com o lar. $\mathrm{O}$ papel maternal é extremamente forte nessa luta insólita.

As mulheres agredidas buscam a justiça com o objetivo de resgatar a dignidade, ao fazerem suas queixas e denúncias. O discurso delas mostra o quanto a violência psicológica e moral dos parceiros é, de fato, algo comum na sociedade. Por um lado, há uma mulher tentando buscar seu espaço social, mas que ainda mantém, no lar, seu papel de mãe. Por outro lado, há um homem embrenhado de preconceitos ao humilhar a parceira, desvalorizando-a e diminuindo sua autoestima.

Para melhor demonstrar como em brigas e em discussões domésticas é muito comum expressões corriqueiras que levam à humilhação, será retratada uma discussão entre um casal cujo $\mathrm{BO}^{4}$, já foi citado neste estudo. Para tanto, transcreve-se parte dessa discussão gravada que instruiu o processo, decretando a Medida Protetiva. Vale Lembrar que serão usados $\mathbf{M}$ para a fala da mulher e $\mathbf{H}$ para a fala do homem.

\begin{tabular}{|l|l|}
\hline Discussão com voz sempre alterada. \\
\hline $\begin{array}{l}\text { H: Você é uma vagabunda. Parece } \\
\text { uma gelatina quando anda, balança } \\
\text { tudo. }\end{array}$ & $\begin{array}{l}\text { M: quê? Vou contar para os meus } \\
\text { pais.... você vai ver (...) }\end{array}$ \\
$\begin{array}{l}\text { Aí você põe essas roupas e fica } \\
\text { parecendo biscate. }\end{array}$ & \\
\hline $\begin{array}{l}\text { H: Vai embora sua arranchada. Não } \\
\text { quero mais você aqui. Essa casa não }\end{array}$ & M: É minha! Eu casei com você. \\
$\begin{array}{l}\text { é sua. Essa casa é minha. Você se } \\
\text { acha bonita, mas é horrorosa, toda } \\
\text { mole. }\end{array}$ & \\
\hline $\begin{array}{l}\text { H: É? Ê, mulher... Mulher... } \\
\text { Mulher... }\end{array}$ & M: É o quê? \\
\hline H: Mulher que tem brio na cara! & M: Eu tenho muito brio! \\
\hline $\begin{array}{l}\text { H: Que brio que você tem. Vocêe } \\
\text { nunca botou nada aqui dentro? É } \\
\text { uma imprestável }\end{array}$ & Que não botei? \\
\hline
\end{tabular}

\footnotetext{
${ }^{4}$ Processo da Vara Maria da Penha B.O no 2015/155722, que concedeu a Medida Protetiva.
} 


\section{SEMINÁRIO DE PESQUISA EM CIÊNCIAS HUMANAS - SEPECH \\ Humanidades, Estado e desafios didático-científicos \\ Londrina, 27 a 29 de julho de 2016}

\begin{tabular}{|c|c|}
\hline$\overline{(\ldots)}$ & $(\ldots)$ \\
\hline $\begin{array}{l}\text { H: Bate perna pra baixo e pra cima. } \\
\text { Parece uma travesti }\end{array}$ & $\begin{array}{l}\text { M: Bato perna não. Vou à luta. Eu } \\
\text { não pareço travesti não. Você que é } \\
\text { um barrigudo de tanto beber. }\end{array}$ \\
\hline$(\ldots)$ & $(\ldots)$ \\
\hline $\begin{array}{l}\text { H: Você consegue me responder } \\
\text { uma pergunta? }\end{array}$ & $\begin{array}{l}\text { M: Eu tenho as minhas lutas e as } \\
\text { minhas dificuldades. } \mathrm{Eu} \text { sou } \\
\text { batalhadora. }\end{array}$ \\
\hline H: Luta? Que luta que você tem? & $\begin{array}{l}\text { M: As lutas que eu tenho diárias } \\
\text { com você bêbado }\end{array}$ \\
\hline H: Luta? Comigo? & M : Diária com a tua grosseria! \\
\hline H: Comigo? A minha? E você? & M: Com seu jeito de me agredir. \\
\hline $\begin{array}{l}\text { H: Você não tem argumento é } \\
\text { vagabunda }\end{array}$ & $\begin{array}{l}\text { M: Eu não posso me produzir } \\
\text { porque eu sou travesti... }\end{array}$ \\
\hline $\begin{array}{l}\text { H: Querida, eu tô cagando para } \\
\text { você... }\end{array}$ & M: Não, não \\
\hline $\begin{array}{l}\text { H: Eu estou cagando para você, Sua } \\
\text { biscate }\end{array}$ & $\begin{array}{l}\text { M: N-ã-o v-o-u embora, esta casa } \\
\text { também é minha }\end{array}$ \\
\hline $\begin{array}{l}\text { H: Eu também não vou. Eu também } \\
\text { não vou! Você vai ver o foda-se. } \\
\text { Você tem tempo pra responder? Por } \\
\text { que que você não vai embora, já que } \\
\text { você fala tanto de mim? }\end{array}$ & $\begin{array}{l}\text { M: Porque eu não tenho dinheiro pra } \\
\text { ir embora... }\end{array}$ \\
\hline $\begin{array}{l}\text { H: Ahhh, ahhh, você não tem } \\
\text { dinheiro? } \\
\text { H: Vai morar na puta-que-pariu! } \\
\text { Você não merece as coisas que eu te } \\
\text { dou. É muito pra você, sua sem } \\
\text { noção. }\end{array}$ & $\begin{array}{l}\text { M: Não, não tenho dinheiro. Não } \\
\text { vou embora esta casa é minha. Casei } \\
\text { com você. }\end{array}$ \\
\hline
\end{tabular}

Ao usar os adjetivos "biscate", "vagabunda" e "travesti", observa-se que $\mathbf{H}$ tem a intenção de inferiorizar a esposa. Ele usa esses termos porque, socialmente, são designações que se aplicam àqueles à margem da sociedade. É como se quisesse desvalorizá-la, colocá-la em posição inferior.

Obviamente, são termos que mostram o preconceito e entoam um discurso violento. Essa violência avança nas falas de $\mathbf{H}$ que também tentam rebaixar a esposa no que se refere à vaidade. Em uma sociedade em que a beleza dita valores, compreende-se o porquê de comparações como "parece uma gelatina" e "parece um travesti". É uma tentativa de depreciar a feminilidade, diminuindo a mulher, fazendo com que esta tenha sua autoestima rebaixada e, portanto, sinta-se inferior, sinta-se incapaz de ser amada e aceita pelo outro.

A mulher colocada como dependente, é um peso no que se refere ao quesito econômico. Este é um argumento comum em discussões domésticas. Nesse sentido, observa-se nas falas de $\mathbf{H}$ que o mesmo tenta se colocar como superior, por se ver como o provedor, como único responsável capaz pela manutenção financeira do lar. 


\section{SEMINÁRIO DE PESQUISA EM CIÊNCIAS HUMANAS - SEPECH \\ Humanidades, Estado e desafios didático-científicos \\ Londrina, 27 a 29 de julho de 2016}

O valor da mulher enquanto dona de casa se perde. Cuidar da casa e da família nada representa na visão do marido que, agressivamente, coloca $\mathbf{M}$ em situação de comodismo.

Nos adjetivos "imprestável” e " arranchada," fica nítido o ponto de vista machista que pretende proporcionar à mulher a sensação de inutilidade, fazendo-a sentir-se incapaz de sobreviver sozinha. Quando $\mathbf{H}$ diz que a esposa é uma arranchada, quer dizer que está morando na casa de favor porque a casa não the pertence. Ele não respeita a esposa. $\mathrm{Na}$ visão dele, como estão se separando, ela não tem direito a ficar na própria casa, porque ele se acha o único dono.

O discurso de baixo calão é também uma forma de perceber as marcas da violência. É uma maneira de ofender e exteriorizar o ódio. O desprezo de $\mathbf{H}$ por $\mathbf{M}$ fica nítido nas sequências frasais ofensivas: "foda-se", "vai morara na puta-que-pariu" e "eu tô cagando para você". Nessas frases, percebe-se o teor ofensivo que sujeita a mulher à degradação do ser humano, como se não tivesse capacidade para nada. Assim, ela se sente dependente e inferior, por isso precisa se sujeitar à humilhação para sobreviver.

Essa discussão ilustra bem tantos outros discursos violentos que estão arraigados na sociedade. Muitas são as mulheres que, seja pela violência física ou psicológica, sofrem e carecem de proteção. Portanto, por meio de discursos como o analisado, observa-se o quanto a criação da Lei Maria da Penha é necessária para coibir a violência contra a mulher, dando a elas um norte para onde e por onde devem seguir para se livrar da violência.

\section{CONCLUSÃO}

Considerando que a Semântica Argumentativa estuda o sentido construído pelo linguístico, não na língua, mas no discurso em si, a análise empreendida demonstra que, segundo Maingueneau (2008, p. 81, apud OLIVEIRA; MACHADO, 2013, p.22):

[...] seria errado pensar que, em um discurso, as palavras não são empregadas a não ser em razão de suas virtualidades de sentido em língua. Porque, além de seu estrito valor semântico, as unidades lexicais tendem a adquirir o estatuo de signos de pertencimento. Entre vários termos a priori equivalentes, os enunciados serão levados a utilizar aqueles que marcam sua posição no campo discursivo.

Assim, ao conduzirmos nosso olhar para contextos que envolvem decisões com base na Lei Maria da Penha, é possível perceber itens lexicais comuns no discurso de mulheres e homens envolvidos nos processos, sendo possível também trilhar prerrogativas, a partir desses itens, sobre como a violência permeia esse discurso, colocando a mulher num papel de inferioridade.

Ao utilizar adjetivos como "biscate", "vagabunda" e "travesti", observa-se claramente a intenção do marido de colocar a mulher em uma situação de inferioridade, como se quisesse desvalorizá-la. Também o discurso de baixo calão ilustra como as palavras podem ser nocivas e dolorosas. 


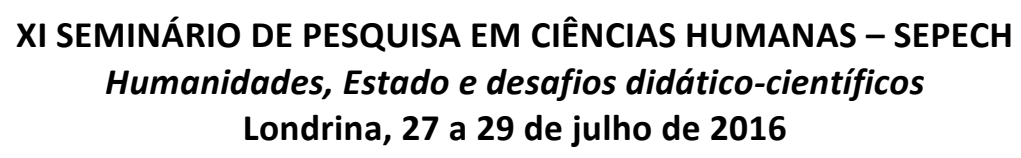

As palavras e expressões utilizadas no discurso de violência adquirem sentido justamente porque inseridas no universo discursivo, tal como ocorre no universo social em que a Lei Maria da Penha foi insculpida. Esta empreitada não se propõe a uma análise terminal. Ao contrário, o intuito é provocar ainda mais debates e movimentar o processo crítico.

\section{REFERÊNCIAS}

BAKHTIN, M. Marxismo e filosofia da linguagem. Trad. Michel Lahud e Yara Frateschi Vieira. São Paulo: HUCITEC, 1997.

BRASIL, Constituição Federal de 1988.

BRASIL, Lei Maria da Penha $n^{0} 11.340 / 2006$.

COLARES, V. Linguagem e direito no Brasil. Relatório parcial do projeto de pesquisa interdisciplinar Análise Crítica do Discurso Jurídico ( $\mathrm{n}^{\circ}$ 2546463711149023), CNPq / Edital MCT/CNPq 50/2006. Núcleo de Pesquisa e Estudo Sociojurídico (NUPESJ) e Mestrado em Direito. Universidade Católica de Pernambuco (UNICAP), 2008.

GUIMARÃES, E. Semântica do acontecimento. Campinas: Pontes, 2002.

IZUMINO, W. P. Os estereótipos de gênero nos processos judiciais e a violência contra a mulher na legislação. Painel 02 In: Maria L. Q. de Moraes, Rubens Naves. (Orgs.). Advocacia pro Bono em defesa da mulher vítima de violência. Campinas, SP. Editora da Unicamp. 2002.

FUZER, C.; BARROS, N. C. Processo penal como sistema de gêneros. Linguagem em (Dis)curso. Tubarão, v. 8, n. 1, Apr. 2008 . Disponível em $<$ http://www.scielo.br/scielo.php?script=sci arttext\&pid=S1518-. Acesso em $18 \mathrm{de}$ abril de 2016.

OLIVEIRA, E. G. Argumentação: da idade média ao século XX. Signum: estudos da linguagem, Londrina, n. 7/2, p. 109-131, 2004.

; MACHADO, R. P. B. O ethos em (cena): a força argumentativa do humor.

Verbum: cadernos de pós-graduação, Campinas, n. 3, p. 4-24, 2013.

SAUSSURE, F. de. Curso de lingüística geral. $2^{\circ}$. ed. São Paulo: Cultrix, 2006. 